\title{
Guillaume Bergeron, Les combats chevaleresques dans l'œuvre de Chrétien de Troyes
}

\section{Maria Colombo Timelli}

\section{(2) OpenEdition}

1 Journals

\section{Édition électronique}

URL : http://journals.openedition.org/studifrancesi/6182

DOI : 10.4000/studifrancesi.6182

ISSN : 2421-5856

Éditeur

Rosenberg \& Sellier

\section{Édition imprimée}

Date de publication : 1 novembre 2010

Pagination : 525-526

ISSN : 0039-2944

\section{Référence électronique}

Maria Colombo Timelli, « Guillaume Bergeron, Les combats chevaleresques dans l'œuvre de Chrétien de Troyes », Studi Francesi [En ligne], 162 (LIV | III) | 2010, mis en ligne le 30 novembre 2015, consulté le 10 janvier 2021. URL : http://journals.openedition.org/studifrancesi/6182 ; DOI : https://doi.org/ 10.4000/studifrancesi.6182

Ce document a été généré automatiquement le 10 janvier 2021.

\section{(c) $($ ) $\odot$}

Studi Francesi è distribuita con Licenza Creative Commons Attribuzione - Non commerciale - Non opere derivate 4.0 Internazionale. 


\title{
Guillaume Bergeron, Les combats chevaleresques dans l'œuvre de Chrétien de Troyes
}

\author{
Maria Colombo Timelli
}

\section{RÉFÉRENCE}

GUILlAUME BERGERON, Les combats chevaleresques dans l'œuvre de Chrétien de Troyes, Berne, Peter Lang, 2008, pp. 256.

1 Dans les romans de Chrétien, les combats chevaleresques - sous les formes variées de la joute et du tournoi - constituent bien évidemment un motif portant du récit; au-delà des constantes thématiques, formelles ou stylistiques, au-delà même d'un réseau symbolique commun, on relève cependant, comme le souligne G.B. dans son Introduction, des dissemblances qui méritent d'être étudiées.

2 Pour ce faire, il est indispensable de vérifier d'abord le poids et les caractéristiques des combats dans la littérature contemporaine, analyse qui fait l'objet du premier chapitre («Les combats dans les œuvres littéraires du XII ${ }^{\mathrm{e}}$ siècle», pp. 21-46). Les résultats de cette enquête ne sauraient surprendre: si dans les romans, ceux de Chrétien notamment, le cadre des aventures individuelles est un royaume en paix-où les conflits éventuels sont vite réglés -, les chansons de geste se caractérisent par un état de guerre quasi permanent, où peu de place est accordée au combat singulier. La perspective aussi est nettement différente: dans le roman le côté politique des exploits chevaleresques existe, mais le souci principal est individuel, alors que dans le genre épique c'est la bataille en tant qu'affrontement entre groupes ennemis qui domine. Le chapitre II («Le combat singulier comme donnée initiale», pp.47-100) part du constat qu'un duel inaugure Erec, Yvain, Perceval; dans les trois cas, le combat assume une fonction réparatrice contre une menace adressée au royaume d'Arthur, et le résultat positif du conflit est déterminé par la légitimité de la cause pour laquelle les 
trois héros se battent: l'individualisme peut ainsi se concilier avec les intérêts de la communauté. Apparemment réalistes, les descriptions de ces combats se révèlent toutefois statiques, et surtout symétriques dans la présentation des adversaires (Erec / Yder, Lancelot / Méléagant, par exemple; aux éléments soulignés par G.B. on pourrait ajouter l'importance de quelques phénomènes linguistiques: la récurrence des verbes à préfixe entre, ou des pronoms andeus / ambedui / li uns l'autre etc.). Si ces conflits à portée morale ne peuvent être vaincus que par le héros 'juste', cette symétrie entre adversaires imposerait de voir dans l'ennemi le double monstrueux du protagoniste.

Comme le récite le titre, le chapitre III concerne plus particulièrement Perceval, considéré comme exceptionnel dans la mesure où Chrétien ne décrit presque pas les duels - il affirme même à plusieurs reprises l'inutilité de ces descriptions -, alors que la violence est bien présente dans le récit. G.B. essaie d'expliquer cette contradiction apparente: à ses yeux le Conte du Graal est une sorte de chant du cygne du monde arthurien, un roman marqué, plus que les autres, par le passage du temps et la nécessité d'économie narrative. Quelques pages sont consacrées aux adversaires internes à la cour arthurienne: Keu, vu comme «la mauvaise conscience de toute une classe sociale, un mal lancinant, mais un mal nécessaire» (p. 125), et Gauvain, personnage positif certes, mais qui se trouve à se battre dans des duels judiciaires et qui prouve «les limites de la chevalerie qu'il représente, mondaine et incapable de dépassement» (p. 133) («Les autres duels et le cas particulier du Conte du Graal», pp. 101-138).

Plus rares dans l'œuvre de Chrétien, les combats contre de petits groupes d'ennemis ou contre des monstres font l'objet du quatrième chapitre («Les affrontements contre des groupes de combattants et contre des créatures monstrueuses», pp.139-181). Avec la seule exception de Harpin de la Montagne dans Yvain, tous les adversaires monstrueux sont anonymes; par ailleurs ces combats, généralement courts, gagnent en réalisme: le souci pour le détail précis rend le combat plus crédible. Quant aux affrontements contre des adversaires regroupés (par exemple, les trois et les cinq brigands que rencontre Erec dans la forêt), il s'agit en réalité d'une succession de combats singuliers, très courts, avec un effet de répétition évident. Dans tous ces cas aussi, les protagonistes se battent pour l'établissement ou la défense de la légitimité, les monstres en particulier représentant tantôt des instincts primitifs, tantôt des principes hostiles à la vie chevaleresque et courtoise.

6 Le cinquième et dernier chapitre («Les batailles et les tournois», pp. 183-235) est consacré aux batailles rangées, pourtant rares dans les romans de Chrétien; leur trait commun consiste dans le fait que la victoire est toujours déterminée par la valeur individuelle du héros sur des antagonistes généralement non définis. G.B. décèle dans ces descriptions des considérations d'ordre stratégique, quelques traits de réalisme, mais aussi des aspects plus proprement narratifs et littéraires, entre autres la fonction des spectateurs. Pour les tournois en particulier, sorte de guerre artificielle, Chrétien proposerait une version "mondanisée" (p. 229) de la réalité historique de son temps. Si c'est toujours l'exploit individuel du protagoniste qui détermine le résultat, ces affrontements ont cependant tous une portée collective et-sur le plan de la narration - ils sont complémentaires dans sa "carrière" chevaleresque.

7 Issu d'une thèse de doctorat (dont il reste une trace sans doute involontaire dans la conclusion, p. 237: «Nous avons vu dans les chapitres de cette thèse...»), ce -livre en garde très nettement la structure et quelques maladresses ou ingénuités (par ex. où, à propos 
des pucelles prisonnières au Château de Pesme Aventure, G.B. reprend «une expression moderne et socialiste» pour affirmer que les deux démons «exploitent des travailleurs», p. 153; ou bien lorsqu'on compare les tournois de Chrétien à «certains combats de boxe d'aujourd'hui», p. 230), de nombreuses redites surtout et des renvois constants et souvent répétitifs d'un chapitre à l'autre. Malheureusement, il est aussi déparé par un nombre important de fautes de tout genre: typographiques (ambiguité sans tréma, p. 41 et ailleurs; saut de blancs: Chrétiende Troyes p. 44, thereader's imagination p. 82, lamarque d'un [sic] Apocalypse p. 113; la giffle p. 107; s,an torne p. 115; moyen-âge p. 134 et ailleurs; Percev'al p. 136), morphologiques (la possibilité... n'est jamais absent p. 35 ; la narration... ressemblent p. 46; s'ensuivent une progression sociale du héros p. 48; peu importe les motivations personnelles p. 67; la transgression qu'il a fait p. 81; l'impression... est accentué p. 82; de manière... fort imagées p. 111; une humiliation... que le sénéchal a subi p.124; une simple désir p. 126; nulle malice est à l'origine de l'assaut p. 127; lequel qui sera reporté... p. 131; et ainsi de suite), ou autres: ainsi, le renvoi dans la note 10 p. 225 (Ibid., pp. 131-2) se rapporte manifestement à Chevaliers et chevalerie au Moyen Âge de -Jean Flori, mais la note précédente, à la p. 206, renvoie à l'-étude sur Yvain de -Jean Frappier; et encore: p. 226, on prétend que The Knight and Chivalry de Richard Barber (1974) est «plus récent» que le -livre de Flori à peine cité, qui est de 1998. Manifestement, la typographie suit le style anglophone, comme le prouvent la division en syllabes et l'absence de certains graphèmes (soeur et jamais sœur, ou œuvres p. 113, par ex.). Inutile de cacher que ces aspects gênent quelque peu la lecture d'un ouvrage qui demeure intéressant dans l'ensemble, mais qui aurait beaucoup gagné d'une relecture attentive du -texte et des épreuves. 